\title{
Food motivation in rats of different ages
}

\author{
ARJAN BLOKLAND and WIJNAND RAAIJMAKERS \\ University of Limburg, Maastricht, The Netherlands
}

\begin{abstract}
In this study, we attempted to compare food motivation in Brown-Norway rats of three different ages $(8,14$, and 26 months old) under two different levels of food deprivation by measuring running speed in a runway. Food motivation was also assessed in a progressive ratio schedule of reinforcement in an operant chamber at one level of deprivation. Compared with the adult and middle-aged rats, the old rats had a slower running speed in the runway and made fewer leverpresses in the progressive ratio test. It was suggested that both age and weight affected the level of food motivation. A differential food deprivation technique (i.e., an age-related increase in the percentage of body weight reduction) may possibly be a way to reduce differences in levels of food motivation in rats of different ages.
\end{abstract}

In what were probably the first studies that evaluated the age-related differences in learning in rats, Stone (1929) recognized that there could be a problem with respect to different levels of motivation, because old rats usually weigh more than young rats. Williams \& Campbell (1961) showed that the acceptance of quinine in food by rats of different ages (ranging from infancy to maturity) was proportional to their percentage weight loss. However, these studies evaluated the need for food rather than food motivation and did not involve rats older than 100 days. In later studies on age-related differences in learning, Goodrick $(1968,1972)$ introduced a differential deprivation technique in food-motivated learning tasks in order to equalize the motivational level of young and old rats. The premise of differential food deprivation is that the reduction of the free-feeding weight is related to age: The older the animal, the greater the percentage reduction in body weight. Although the rationale behind the differential deprivation technique seems valid, most aging studies have been performed without using a differential deprivation technique, which controls for possible age-related differences in motivation (see, e.g., Dunnett, Evenden, \& Iversen, 1988; Hamm, Knisely, \& Dixon, 1983; Wallace, Krauter, \& Campbell, 1980). A deprivation technique that has often been used is to allow subjects to eat/drink for a fixed time per day. However, Campbell, Teghtsoonian, and Williams (1961) showed that this may not be an appropriate way to establish comparable levels of deprivation in rats of different ages (see also Elias \& Elias, 1977).

Van der Staay, Van Nies, and Raaijmakers (1990) used a differential deprivation technique to evaluate the agerelated decline in spatial-discrimination learning of BrownNorway rats in a holeboard task. They found that in the

\footnotetext{
The purchase of the old rats was supported by a grant from the Dutch Scientific Research Organization (NWO-Fonds voor oude proefdieren). Correspondence should be addressed to W. Raaijmakers, Department of Neuropsychology and Psychobiology, University of Limburg, P.O. Box 616, NL-6200 MD, Maastricht, The Netherlands.
}

course of training, spatial-discrimination performance diverged between age groups whereas the speed of responding converged. Thus, although the old rats had an impaired spatial-discrimination performance, the speed of responding did not vary between the age groups at the end of training. These findings were considered to support the use of a differential deprivation technique to compare the performance of subjects of different ages in learning tasks. However, to our knowledge, there have been no studies that have systematically evaluated age-related differences in food motivation by applying a differential food-deprivation technique.

Different paradigms have been used to study motivational behavior. In a straight-alley runway, the running speed of the subjects is taken as a measure of motivation: The higher the running speed, the greater the food motivation. In a progressive ratio schedule of reinforcement (Hodos, 1961; Van Hest, Van Haaren, \& Van de Poll, 1988), the number of leverpresses the rat is willing to make to receive a reward is taken as a measure of motivation. Both tasks have a strong motoric component. Because motor performance generally declines with age in rats (see, e.g., Gage, Dunnett, \& Björklund, 1984), the evaluation of age-related differences in motivation may be complicated when these measures are used.

In the present study, we evaluated food motivation, using a runway, in Brown-Norway rats of three different ages at different deprivation levels $(90 \%$ and $80 \%$ of the free-feeding body weight). We tested the rats twice at both deprivation levels: First in an ascending order (from $90 \%$ to $80 \%$ ) and then in a descending order (from $80 \%$ to $90 \%$ ). This made it possible to evaluate the increase or decrease in running speed within subjects (age groups) as a measure of food motivation. Within-subject analysis diminishes bias caused by differences in motor performance. We used Brown-Norway rats for two reasons. First, they have significantly fewer age-related lesions than do albino strains (Bronson, 1990). Second, we had found that the speed of responding reached comparable levels in young and old rats in a holeboard experiment 
(Van der Staay et al., 1990), indicating that, up to an advanced age, there are no gross motor dysfunctions in this strain, which minimizes age differences in the speed of responding. We also subjected the rats to a progressive ratio schedule of reinforcement in an operant chamber during one $(80 \%)$ deprivation level.

\section{METHOD}

\section{Subjects}

We used male Brown-Norway (BN/BiRij) rats of three different ages 18 months (adult), $n=7 ; 14$ months (middle-aged), $n=8$; 26 months (oid), $n=71$. All rats were housed individually in standard Makrolon cages on sawdust bedding in an air-conditioned room (about $20^{\circ} \mathrm{C}$ ). The rats had free access to food (RMH-TM, Hope Farms) and tap water. They were kept under a 12:12-h light:dark cycle (lights on from 9:00 to 21:00). All rats were healthy and were regularly checked for their SPF status during testing.

\section{Food Deprivation}

The body weight of the rats was gradually reduced to $90 \%$ of their free-feeding weight over a period of 2 weeks before they were subjected to the first series of tests. After the first test series, the body weight of the rats was further reduced to $80 \%$ of their freefeeding weight. During the first deprivation period, the 8-monthold rats were allowed to gain weight ( $5 \mathrm{~g}$ per week). The rats were allowed food ad lib for 3 weeks after they had completed the second series of tests, at which time their free-feeding weight was determined again. This weight was used as the reference value for the subsequent deprivation period. After the third test series, in which the body weight of the rats was gradually reduced to $80 \%$ of their free-feeding weight over a period of 2 weeks, the rats were allowed to gain weight to reach $90 \%$ of their free-feeding weight, after which the final series of tests was carried out.

\section{Behavioral Procedures}

Runway. The straight-alley runway $(245 \times 12 \times 15 \mathrm{~cm})$ was made of lacquered wond and was connected to a polyvinylchloride goalbox that contained a food tray. A metal obstruction could be placed at any place on the runway to adjust its length.

Before testing, the rats were given a total of 23 adaptation trials in the runway. A rat was left in the goalbox until it had consumed the food reward (six 45-mg BioServe food pellets). A rat was always started with its head away from the goalbox. In adaptation sessions, the length of the runway was gradually increased from 20 to $120 \mathrm{~cm}$; during training trials, the length of the runway was $120 \mathrm{~cm}$. Special attention was given to keep test conditions constant (e.g., background noise, similar testing procedures, and same position of runway in the room). The runway was cleaned after each session. All testing was carried out in a darkened room. In each session, a rat was given three trials in succession. A test series consisted of a total of five sessions of three trials. The latency to enter the goalbox with four paws was measured.

Progressive ratio. The experiments were carried out in four identical conditioning chambers $(40 \times 30 \times 33 \mathrm{~cm})$. The ceiling of each of these Skinner boxes contained a light that illuminated the box during the experiments. The left and right side walls served as control panels and included manipulanda and discriminanda. A recess $(5 \times 5 \mathrm{~cm})$ was built into the left side panel $2.5 \mathrm{~cm}$ above the grid floor and contained a food tray, into which a pellet dispenser delivered 45-mg food pellets (BioServe). Two retractable stainless steel levers $(4 \mathrm{~cm}$ wide) projected $2 \mathrm{~cm}$ into the Skinner box. The levers were located $6 \mathrm{~cm}$ from both sides of the recess, $12 \mathrm{~cm}$ above the grid floor. The conditioning chambers were enclosed in soundattenuating housing. An exhaust fan produced background noise.
An MS-DOS microcomputer controlled the experimental equipment and collected the data.

The rats were trained and tested on the progressive-ratio schedule during the second test series when they were on the $80 \%$ fooddeprivation level. The rats received two 30 -min magazine training sessions before they were trainal on a continuous reinforcement schedule to press the left lever on the left wall. After the rats had acquired the leverpress response, they were subjected to the progressive-ratio schedule (PR-5, 5 referring to the incremental steps of leverpresses necessary to obtain one food pellet) so that food motivation in (wo sessions could be evaluated. A PR-5 session was ended when the time between two leverpresses exceeded $10 \mathrm{~min}$. The total number of leverpresses during a session was measured.

All behavioral testing was carried out between 12:00 and 17:00. The rats were given their daily amount of food $1 \mathrm{~h}$ after testing.

\section{Statistical Analysis}

Body weight. Age differences in body weight were analyzed in a one-factorial (age) analysis of variance (ANOVA). A DuncanWaller post hoc analysis evaluated the age differences in more detail.

Runway. The mean time to enter the goalbox was calculated for each test session according to the formula $\left(t_{1}+t_{2}+t_{3}\right) / 3$ (the subscript refers to the trial). The mean running speed per session was calculated by dividing 120 (length of runway) by the mean trial time. The mean running speed was calculated for the four test sessions. For data analysis, the running speed was transformed logarithmically to remove nonhomogeneity.

We first evaluated whether there were age differences in running speed in the four test series. The increase ( $90 \%$ to $80 \%$ deprivation level) or decrease $(80 \%$ to $90 \%$ deprivation level) in running speed was also evaluated by using $t$ statistics. Age differences in food motivation were assessed by comparing the mean increase in running speed from Test Series $1(90 \%)$ to Test Series $2(80 \%)$, and the decrease from Test Series $3(80 \%)$ to Test Series $4(90 \%)$ within subjects was assessed with a one-factorial (age) ANOVA. A Duncan-Waller post hoc analysis evaluated the age-related dif ferences in more detail. Differences in running speed at similar deprivation levels were evaluated by using $t$ statistics.

Progressive ratio. The mean number of leverpresses during the two PR-5 sessions was calculated and transformed logarithmically to remove inhomogeneity. The data were analyzed with a onefactorial (age) ANOVA. A Duncan-Waller post hoc analysis evaluated the data in more detail.

Correlational analysis. The data from the runway and PR-5 test were correlated using Pearson's correlation coefficients.

\section{RESULTS}

Body weight. The free-feeding body weight of the animals is shown in Table 1. There was an age-related increase in free-feeding body weight $[F(2,21)=49.11, p<$ $.01]$ at the start of both deprivation periods. Post hoc analysis revealed that the body weight was different for all age groups.

Runway. A consistent decrease in mean running speed across age groups was found during all four test series

Table 1

Free-Feeding Body Weight (in Grams) of the Brown-Norway Rats of Different Ages at the Start of the Two Deprivation Periods

\begin{tabular}{ccccccc}
\hline Period & Adult & SEM & Middle-Aged & SEM & Old & SEM \\
\hline 1 & 334 & 5.6 & 395 & 9.9 & 475 & 13.7 \\
2 & 367 & 7.1 & 404 & 8.6 & 463 & 13.5 \\
\hline
\end{tabular}


( $F$ values $>4.36, p<.05$ ). The running speed of the old rats increased from Test Series 1 to $2[t(6)=6.79$, $p<.01$; see Figure 1]. The running speed of adult rats tended to increase from Test Series 1 to $2[t(6)=2.12$, $.10>p>.05$ ], but the running speed of the middleaged rats was not affected by an increased level of food deprivation $[t(7)=0.32$, n.s.]. The age groups differed in the increase in running speed from Test Series 1 to 2 $[F(2,21)=3.76, p<.05]$. Post hoc analysis revealed that the increase in running speed was similar for adult and old rats but that the increase was greater for old rats than for middle-aged rats. From Test Series 3 to 4, the running speed of rats from the three age groups showed a decrease $(t$ values $>3.08, p<.05)$ that was similar for all age groups $[F(2,21)<1$, n.s. $]$.

Post hoc analyses of the running speed during the different test series showed that the running speed of the old rats was always slower than that of the adult rats. Except for Test Series 1 , the running speed of middle-aged rats was slower than that of the adult rats. The running speed of old rats did not differ from the running speed of middleaged rats during Test Series 2 and 4. During Test Series 3, the running speed was different for all age groups.

Evaluation of the running speed at similar deprivation levels revealed that only the running speed of the old rats was slower during Test Series 1 than during Test Series 4, both at the $90 \%$ level $[t(6)=2.98, p<.05]$.

Progressive ratio. There was a decrease in the number of leverpresses across age groups during the PR-5 sessions [means, with SEMs in parentheses: adult, 166.4 (54.3); middle-aged, 190.1 (27.6); old, 70.1 (18.1); $F(2,21)=5.29, p<.01]$. Post hoc analysis showed that adult and middle-aged rats pressed the lever more often than did the old rats.

Correlational analysis. There was a strong correlation between the four different mean running speeds in the runway $(r>.70$; all associated $p s<.01)$. The mean running speed during Test Series 1 was negatively correlated with the number of leverpresses in the PR test $(r=-.45$, $p<.05$ ). No correlations were found between mean running speeds during the other three test series in the runway and PR-5 performance ( $r>-.33$, n.s.).

\section{DISCUSSION}

The old rats had the slowest mean running speed during the four runway test series and made fewer leverpresses in the PR-5 test than did the adult and the middle-aged rats. These data could indicate that there is an age-related decrease in food motivation. However, when comparing food motivation in rats of different ages, one is confronted with differences in age, weight, and motor functions. These factors may all contribute to differences in performance on the operationalized measures in the two tests that we used to evaluate food motivation. Consequently, it could be argued that it is impossible to determine which factor(s) contributed to the differences observed.
As mentioned above, we tried to minimize possible age differences in motor functions by using Brown-Norway rats and tests that did not require great motoric effort. It is, however, impossible to dissociate the factors of age and weight because old rats usually weigh more than younger rats. Given this, it is interesting to note that the food motivation of the middle-aged rats was comparable to that of the adult rats during Test Series 1 and sometimes comparable to that of the old rats. The results of the PR-5 test even showed that the mean number of leverpresses was greater for the middle-aged rats than for the adult rats. Apparently, the factor of weight cannot fully explain our results and suggests that age also affects the operationalized measures of food motivation. We therefore conclude that both age and weight affected the operationalized measures of food motivation.

It has been found that old rats are less responsive to opioid-induced feeding behavior than are young rats (Gosnell, Levine, \& Morley, 1983), which suggests that there are age-related differences in the endogenous opioid system. This could also lead to age-related changes in the hedonic quality of food. These two factors could be regarded as age factors affecting food motivation. With respect to weight, it should be mentioned that the agerelated increase in body fat may be an important factor determining food motivation. To control for age-related differences in body weight (fat), food motivation could be evaluated in different rat strains that differ in body weight. This could possibly be a way to dissociate the factor of body weight from the factor of age.

The within-subject analysis showed that the increase in running speed from Test Series 1 to 2 was equal in the adult and old rats, whereas the middle-aged rats did not increase their running speed. From Test Series 3 to 4 , the decrease in running speed was found to be similar for all age groups. The similar increase/decrease in running speed in the adult and the old rats indicates that the percentage weight reduction had similar effects on the operationalized measure of food motivation in adult and old rats.

Inspection of Figure 1 reveals that the running speed of the old rats at the $80 \%$ deprivation level was more comparable with the running speed of the adult rats at the $90 \%$ deprivation level than with the running speed of either age group at similar deprivation levels. These observations may suggest that a differential food-deprivation technique possibly reduces differences in food motivation in rats of different ages.

Recently, Ando and Ohashi (1991) showed that the level of food deprivation predicted the percentage of good learners in a learning task differently in young and old rats. The percentage of good learners was similar in young and old rats when the body weight of the old rats was reduced more than that of the young rats. Although they concluded that this indicated that a differential fooddeprivation technique should be used, their data should be interpreted with caution. Their assumption that the level of food deprivation is related to learning performance may 


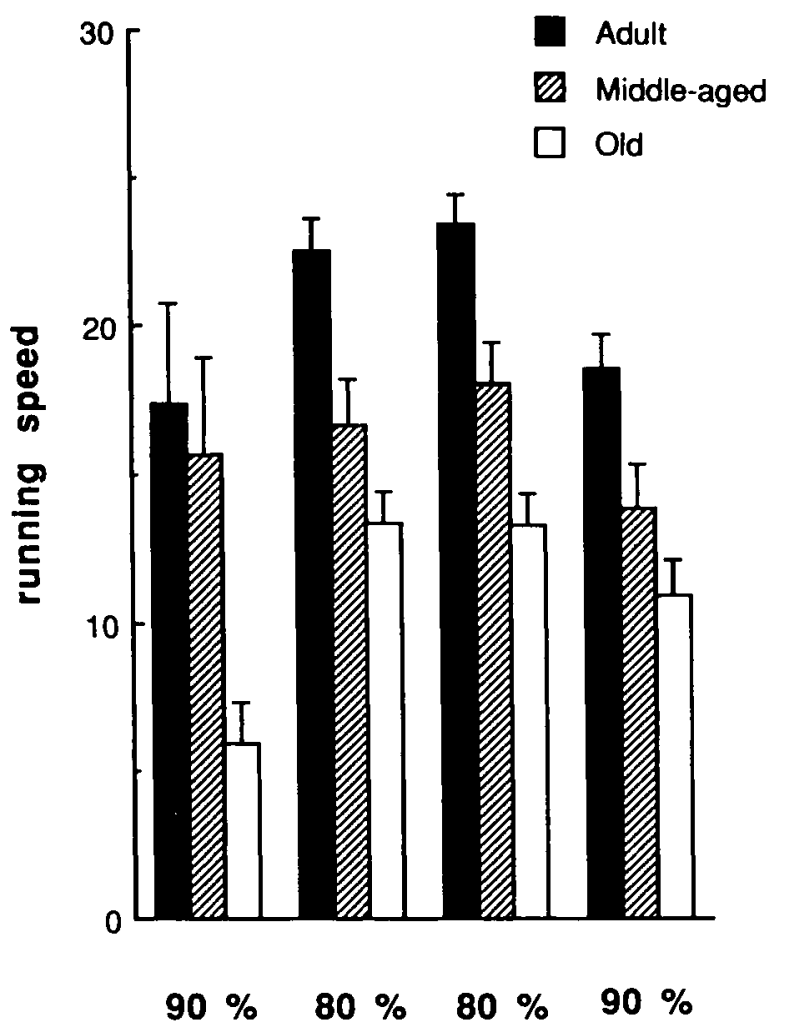

Figure 1. Mean running speed (centimeters/second; $+S E M$ ) of adult, middle-aged, and old Brown-Norway rats in a runway in four test series, each consisting of five sessions of three trials. Two different food-deprivation levels (80\% and 90\%) were assessed.

not be completely correct, since food motivation may depend on various processes (Bolles, 1975b). However, irrespective of their conclusion, these results show that different levels of food deprivation may affect learning performance.

The observation that the old rats were slower during Test Series 1 than during Test Series 4 , when deprivation levels were equal, suggests that food motivation, as measured in the runway, may have a component(s) that interferes with running speed. One factor that could account for this is that old rats need more training to achieve a maximal level of performance. This is supported by the finding that the speed of responding of different age groups of Brown-Norway rats converges during training in a learning task and that old rats increase their speed of responding faster than do animals of other age groups (Van der Staay et al., 1990). It is conceivable that, in learning tasks, age-related differences during the first phase of learning may be confounded by age-related differences in the time needed to achieve maximal levels of responding. Because the running speed of old rats was similar during Test Series 2 and 3 (both at an $80 \%$ deprivation level), we assume that this age-related difference in training duration only affected the results of the first runway test series.
The notion that learning may affect the interpretation of data obtained from experiments assumed to measure motivation (Bolles, 1975b) was supported by the poor correlation between the data from the runway and the PR-5 tests. The observation that there was a correlation between the first runway test series and the PR-5 test is probably due to the very slow running speed of the old rats in the first runway test series, which may bias the correlation coefficient that was calculated over age groups. It may be that the two different operationalizations of food motivation measure different aspects. This may be explained by the different factors of the tasks, which might well be differently sensitive to motivational changes (see, e.g., Bolles, 1975a). Such factors could be the difference in the response to obtain a reinforcement (rate measures on the one hand and speed or latency measures on the other), amount of reinforcement per response, and test environment.

In conclusion, the present study showed that there are differences in food motivation in rats of different ages. Although it was not likely that these differences were due to differences in motor functions, it remains unclear whether these differences were due to age and/or weight. A differential food-deprivation technique may possibly reduce differences in levels of food motivation in rats of different ages. We therefore suggest that this food-deprivation technique be used in aging studies.

\section{REFERENCES}

ANDO, S., \& OHASHI, Y. (1991). Longitudinal study on age-related changes of working and reference memory in the rat. Neuroscience Letters, 128, 17-20.

Bolles, R. C. (1975a). Learning theory. New York: Holt, Rinehart \& Winston.

Bolles, R. C. (1975b). Theory of motivation (2nd ed.). New York: Harper \& Row.

Bronson, R. T. (1990). Rate of occurrence of lesions in 20 inbred and hybrid genoxypes of rats and mice sacrificed at 6-month intervals during the first years of life. In D. E. Harrison (Ed.), Genetic effects on aging II (pp. 279-358). Caldwell, NJ: Telford Press

Campbell, B. A., Teghtsoonian, R., Wiluams, R. A. (1961). Activity, weight loss, and survival time of food-deprived rats as a function of age. Joumal of Comparative \& Physiological Psychology, 54, 216-219.

Dunnett, S. B., Evenden, J. L., Iversen, S. D. (1988). Delaydependent short-term memory deficits in aged rats. Psychopharmacology, 96, 174-180.

Elias, M. F., EliAs, P. K. (1977). Motivation and activity. In R. L. Sprott (Ed.), Age, learning ability, and intelligence (pp. 26-40). New York: Van Nostrand Reinhold

Gage, F. H., Dunnett, S. B., \& Börkxlund, A. (1984). Spatial leaming and motor deficits in aged rats. Neurobiology of Aging, 5, 43-48.

GooDRICK, C. L. (1968). Learning, retention, and extinction of a complex maze habit for mature-young and senescent Wistar albino rats. Journal of Gerontology, 23, 298-304.

Goodrick, C. L. (1972). Learning by mature-young and aged Wistar rats as a function of test complexity. Joumal of Gerontology, 27. 353-357.

Gosnell, B. A., Levine, A. S., Morley, J. E. (1983). The effects of aging on opioid modulation of feeding in rats. Life Sciences, 32 , 2793-2799.

HAmm, R. J., KNisely, J. S., \& Dixon, C. E. (1983). An animal model of age changes in short-term memory: The DRL schedule. Experimental Aging Research, 9, 23-25. 
Hodos, W. (1961). Progressive ratio as a measure of reward strength. Science, 134, 943-944

Stone, C. P. (1929). Age factor in animal learning. Genetic Psychology Monographs, 5, 1-130.

Van der StaAy, F. J., Van Nies, J., \& RaAumakers, W. G. M. (1990). The effects of aging in rats on working and reference memory performance in a spatial holeboard discrimination task. Behavioral \& Neural Biology, 53, 356-370.

Van Hest, A., Van Haaren, F., \& Van de Poll, N. E. (1988). The behavior of male and female rats pressing a lever for food is not affected by sex differences in food motivation. Behavioural Brain Research, 27, 215-221.
Wallace, J. E., Krauter, E. E., \& Campbell, B. A. (1980). Animal models of declining memory in the aged: Short-term memory and spatial memory in the aged rat. Joumal of Gerontology. 35, 355-363.

Willams, R. A., \& CAMPBELl, B. A. (1961). Weight loss and quininemilk ingestion as measures of "hunger" in infant and adult rats. Journal of Comparative \& Physiological Psychology, 54, 220-222.

(Manuscript received February 15, 1993; revision accepted for publication June 1, 1993.) 